\title{
PHYSICAL STATISTICS OF SCHOOLCHILDREN AS A HEALTH INDICATOR FOR SMALL COMMUNITIES (II)
}

\author{
HIROAKI KAHYO \\ Department of Preventive Medicine and Public Health \\ School of Medicine, Keio University, Tokyo, Japan
}

(Received for publication February 28, 1969)

\section{INTRODUCTION}

It may be said that measurement of the levels of health of a given community is highly important for promoting community health activities, regardless of the size of population of the community in question. The author investigated whether or not the physical statistics of schoolchildren in the field of school health were suitable as a health indicator in measuring the levels of health of a community with a relatively small size of population and, as stated in the previous report, 1 it was found to be considerably usable. The author has measured separately the levels of health of one city in various districts for elementary schools, using the physical statistics of schoolchildren, and the present report deals with the sample survey investigated for the comparisons among the three items; the result of the above-mentioned measurement, the result of the measurement using various indicators based on the vital statistics, and the environmental conditions of the pertinent small community.

\section{THE COMMUNITY SURVEYED AND DATA}

1) The surveyed community presented in this report was Hadano City, Kanagawa Pref., and measurement of levels of health was estimated in accordance with the elementary school districts in the city. This city occupies nearly the whole area of the small basin (Hadano Basin) located in the central western part of Kanagawa Pref., with an area of $104.2 \mathrm{~km}^{2}$. As is seen in the map in Fig. 1, the northern part is included in part of the 


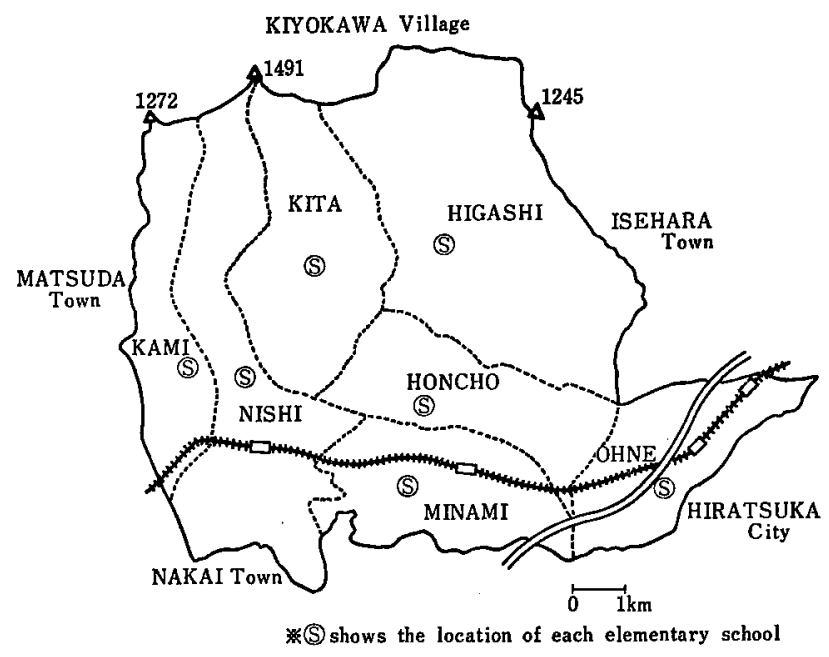

Fig. 1 Map of Hadano City.

Tanzawa Highlands. Due to the geographical conditions, this city has been little contact with the outside society and culture in its history, and there remain considerably conservative factors in the citizens' senses and emotions compared with in people of other arsas. It was 1955 when this area was municipalized, combining Hadano-machi (corresponds to the Honcho area of the present), Minami Hadano-machi, Higashi Hadano-machi, Ohne Village and Kita Hadano Village into one Hadano City. Later this city was combined with Nishi Hadano Town in 1963 (this town used to be Nishi Hadano Village and Kami Hadano Village in 1955) to be municipalized as Hadano City with the present administrative districts. There is a public elementary school in each of the former seven villages and towns before incorporation. The author measured the levels of health of each district using the physical statistics of the public elementary schools.

Table 1 presents the number of households, the population and the changes in the vital statistics for years $1960-66$ of this city with the present administrative scale. Table 2 shows the number of inhabitants for 1959 and 1966 in seven districts.

2) As mentioned previously, for the physical statistical data of schoolchildren, the data for the five years, 1961-65, kept at the seven public elementary schools were used. However, since the data for 1961 of Minami Elementary School were missing, the data of four years were used for this school. These physical statistical data were obtained by summarizing the 
PHYSICAL STATISTICS AS COMMUNITY HEALTH INDICATOR

Table 1

Households, population and vital statistics in Hadano City (1960-1966)

\begin{tabular}{l|rrrrrrr}
\hline & 1960 & 1961 & 1962 & 1963 & 1964 & 1965 & 1966 \\
\hline $\begin{array}{l}\text { No. of households } \\
\text { (as of Oct. 1) }\end{array}$ & 9,786 & 10,011 & 10,342 & 10,767 & 11,558 & 13,521 & 13,233 \\
\hline Population (as of Oct. 1) & 51,287 & 51,896 & 52,952 & 53,444 & 56,080 & 57,930 & 59,632 \\
\hline Births & 717 & 800 & 824 & 838 & 991 & 1,016 & 813 \\
\hline Deaths & 382 & 393 & 413 & 364 & 382 & 401 & 393 \\
\hline Infantile deaths & 24 & 21 & 18 & 20 & 16 & 16 & 12 \\
\hline Neonatal deaths & 13 & 11 & 11 & 13 & 12 & 9 & 9 \\
\hline Still-births & 89 & 68 & 78 & 89 & 66 & 46 & 51 \\
\hline
\end{tabular}

* Quoted from the Annual Report of Public Health for Kanagawa Prefecture.

Table 2

Population according to seven districts in Hadano City

\begin{tabular}{|c|c|c|}
\hline District $\quad$ Year & $\begin{array}{c}1959 \\
\text { (as of Dec. 31) }\end{array}$ & $\begin{array}{c}1966 \\
\text { (as of Dec. 31) }\end{array}$ \\
\hline Honcho & 17,132 & 18,776 \\
\hline Minami & 8,457 & 10,476 \\
\hline Higashi & 5,171 & 5,049 \\
\hline Kita & 3,645 & 3,930 \\
\hline Ohne & 4,640 & 5,789 \\
\hline Nishi & 9,417 & 12,043 \\
\hline Kami & 2,265 & 3,887 \\
\hline Total & 50,727 & 59,950 \\
\hline
\end{tabular}

* Quoted from the Annual Report of Hadano Health Center.

results of the annual physical checkings measured compulsory by the school health service scheme.

3) The figures of health indicators based on the vital statistics according to each of the seven districts were chiefly obtained from the Annual Reports of Hadano Health Center for 1959-61.2 Obscure or insufficient points in these annual reports were filled by necessary figures derived 
from the individual cards of the vital statistics kept at the particular health center.

4) Since there were no coherent data concerning the environmental conditions for each of the seven districts, the author performed a questionnaire survey in June 1966 on the households of 6 th graders of the same city so as to obtain necessary information from the socio-economical considerations, such as the year of the transfer of household into the present address, the native place and occupation of parents.

\section{METHODS OF STUDY}

1) The method for expressing the physical statistical data of schoolchildren depended on the integrated physical values according to sex and measurement item which the author has already reported separately.1, The basic group adopted for the present report is Kanagawa Prefecture.

2) The following eight items were chosen as the health indicators based on the vital statistics; birth rate, delivery rate in institution (which means the ratio of births given in hospitals or clinics to the total number of births), crude death rate, infant mortality rate, proportional mortality indicator (P.M.I.), ${ }^{4}$ the mortality rate of A-group causes (the same as the mortality rate of communicable diseases), the mortality rate of B-group causes (the same as the mortality rate of adult diseases) and still-birth rate. Concerning each of these indicators, the relative ranking in the seven districts for each year from 1959 to 1966 was obtained. Also the ranking of the added value of the figures for 8 years was calculated. In addition, the t-test among the districts, if necessary, was performed on these indicators.

\section{RESULTS}

1) Table 3 represents the integrated physical values according to sex and four measurement items computed for each of the seven elementary schools. In regard to the annual changes of the integrated physical values according to four measurement items, it is observed that there was considerably large size of the fluctuation of girth of chest and sitting height comparing to that of height. Computing the values for three groups, the sizes of fluctuation of the four measurement items for each sex $\left(\Sigma M_{i}, \Sigma F_{i}\right)$ and the added size of fluctuation $\Sigma\left(\sqrt{ } M_{i}^{2} \mp F_{i}^{2}\right)$, with the size of fluctuation of height as the base for each group, a comparison of fluctuation in the other three measurement items was made, which is shown in Fig. 2. In this case 


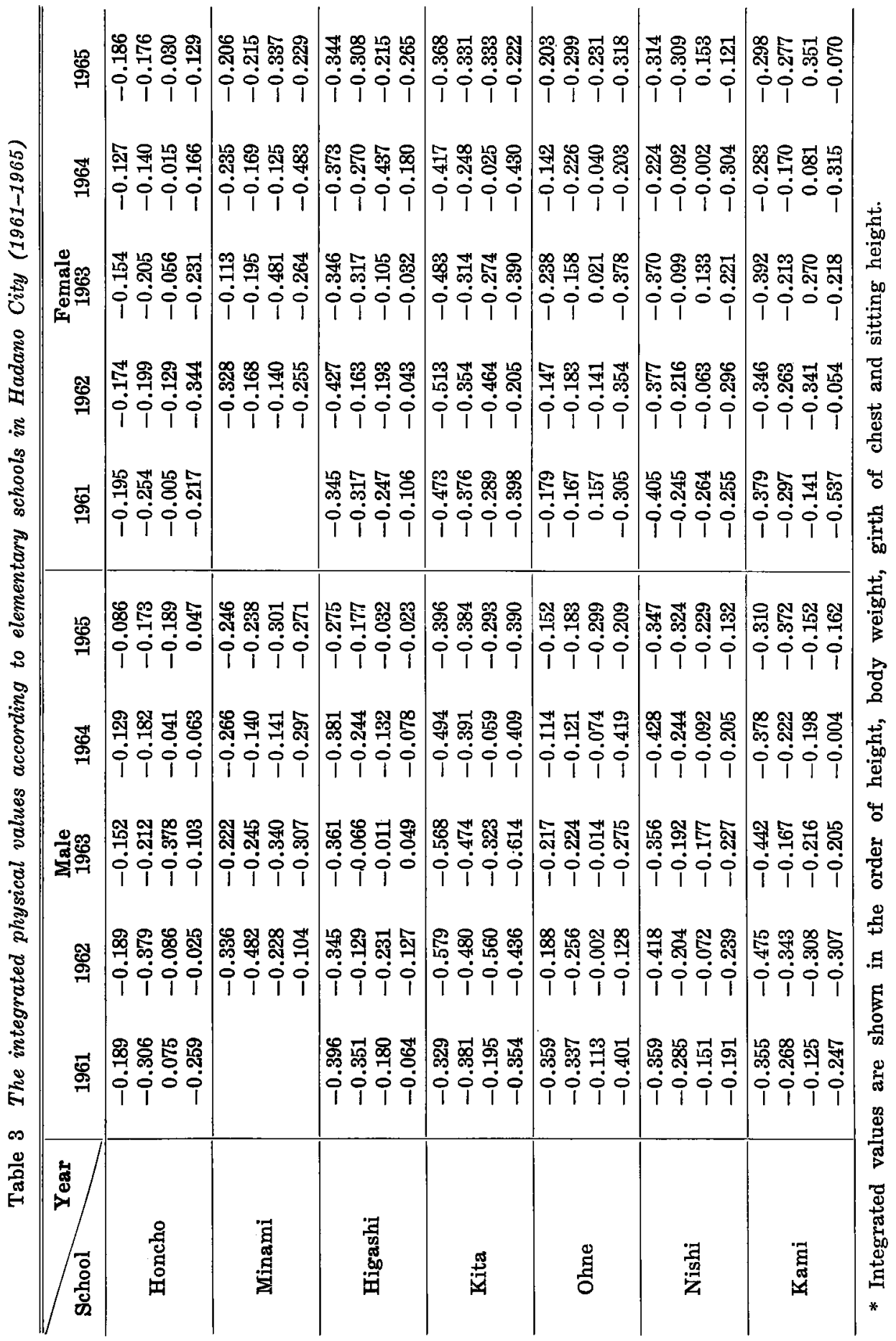




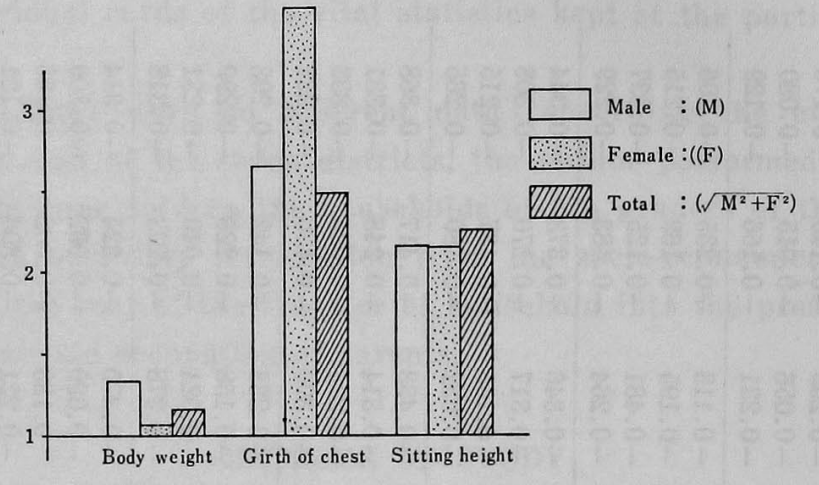

*The fluctuation of the integrated value of height is the base for others.

Fig. 2 Comparison of the annual fluctuation of the integrated physical values according to sex. Elementary schools in Hadano City, 1961-1965.

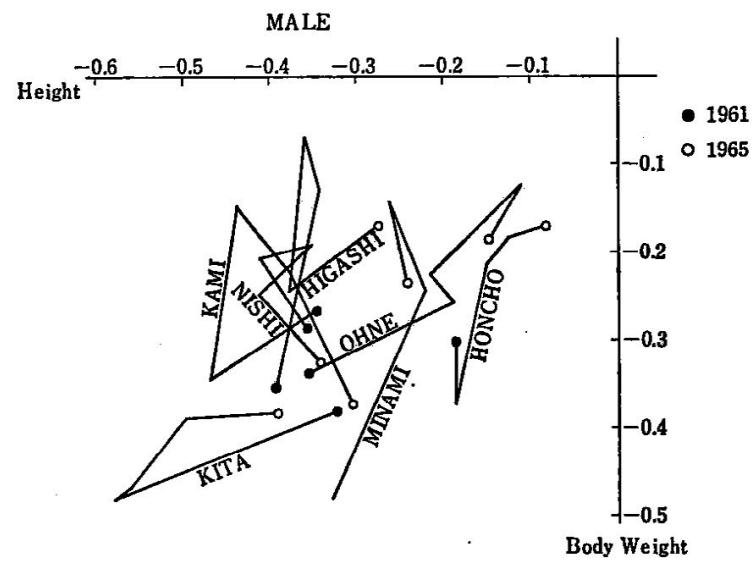

FEMALE

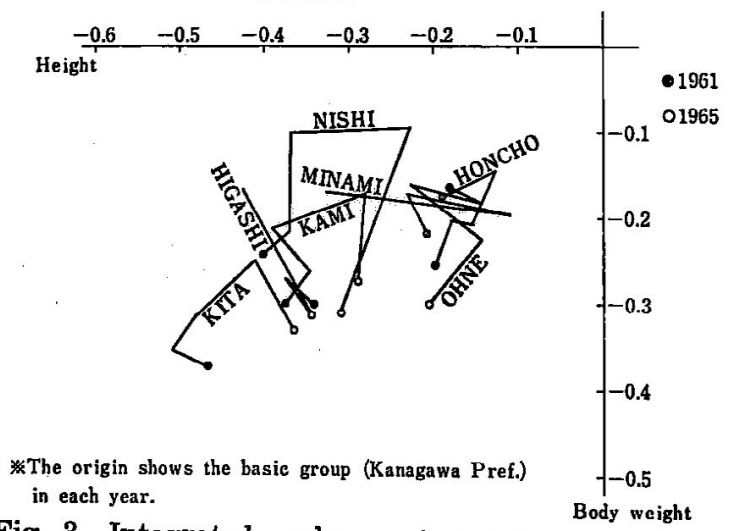

Fig. 3 Integrated values of height and body weight. Elementary schools in Hadano City, 1961-1965. 
too, the widths of the annual changes of girth of chest and sitting height are larger than that of height, over twice as large as the former two values, especially marked in the width of fluctuation of females' girth of chest.

Fig. 3 is a presentation as an example of the integrated values of height on the abscissa and those of body weight on the ordinate for each school according to sex. These figures indicate that the integrated values both for height and body weight in the seven districts of Hadano City are below the average values of Kanagawa Pref., and that there is clearly a considerable difference among these seven districts. Even a statistically significant difference is observed among a certain schools.

Table 4 shows the ranking of the seven districts regarding the arithmetic mean of the integrated values for each of the four measurements in 5 years (or 4 years) by sex.

Table 4

Ranking of the integrated physical values of schoolchildren (Mean of addition of 1961-1965)

\begin{tabular}{l|cccc|cccc}
\hline & \multicolumn{5}{|c}{ Male } & \multicolumn{5}{|c}{ Female } \\
\cline { 2 - 8 } & Height & $\begin{array}{c}\text { Body } \\
\text { weight }\end{array}$ & $\begin{array}{c}\text { Girth of } \\
\text { chest }\end{array}$ & $\begin{array}{c}\text { Sitting } \\
\text { height }\end{array}$ & Height & $\begin{array}{c}\text { Body } \\
\text { weight }\end{array}$ & $\begin{array}{c}\text { Girth of } \\
\text { chest }\end{array}$ & $\begin{array}{c}\text { Sitting } \\
\text { height }\end{array}$ \\
\hline Honcho & 1 & 3.5 & 3 & 2 & 1 & 3 & 3.5 & 2 \\
\hline Minami & 3 & 5 & 6 & 5 & 3 & 1 & 6 & 5 \\
\hline Higashi & 4 & 1 & 2 & 1 & 5 & 6 & 5 & 1 \\
\hline Kita & 7 & 7 & 7 & 7 & 7 & 7 & 7 & 7 \\
\hline Ohne & 2 & 2 & 1 & 6 & 2 & 4 & 3.5 & 6 \\
\hline Nishi & 5 & 3.5 & 4 & 4 & 4 & 2 & 2 & 3.5 \\
\hline Kami & 6 & 6 & 5 & 3 & 6 & 5 & 1 & 3.5 \\
\hline
\end{tabular}

When the rank correlation coefficients (Spearman) according to sex and among the four measurement items are computed for comparison, it is observed that the height and the sitting height of both sexes correlate highly in ranking but the body weight and the girth of chest do not so much. The extent in correlation of the rankings of the four measurement items is relatively high in height and body weight, height and girth of chest, and body weight and girth of chest for males. For females, it is relatively high in height and body weight. The correlation of rankings was insignificant in other occasions. 
Table 5

Ranking of the infant mortality rate according to seven districts of Hadano City

\begin{tabular}{l|ccccccccc}
\hline \hline & 1959 & 1960 & 1961 & 1962 & 1963 & 1964 & 1965 & $1966 \begin{array}{c}1959- \\
1966 \\
\text { addition }\end{array}$ \\
\hline Honcho & 2 & 2 & 6 & 5 & 5 & 6 & 4 & 4 & 2 \\
\hline Minami & 5 & 3 & 1 & 6 & 3 & 7 & 1 & 3 & 3 \\
\hline Higashi & 3 & 5 & 2 & 4 & 7 & $(2.5)$ & 3 & 7 & 5 \\
\hline Kita & 7 & 6 & 4 & $(1.5)$ & $(1.5)$ & $(2.5)$ & 7 & $(1.5)$ & 6 \\
\hline Ohne & 6 & 7 & 5 & $(1.5)$ & $(1.5)$ & $(2.5)$ & 5 & 6 & 4 \\
\hline Nishi & 4 & 1 & 3 & 3 & 4 & 5 & 2 & 5 & 1 \\
\hline Kami & $(1)^{*}$ & 4 & 7 & 7 & 6 & $(2.5)$ & 6 & $(1.5)$ & 7 \\
\hline
\end{tabular}

* ( ) shows zero for infant deaths.

2) Next, the eight health indicators based on the vital statistics were examined for their individual ranking in the seven districts for each year. As an example, Table 5 shows the ranking of the infant mortality rate. It

Table 6

Ranking of the eight health indicators based on the vital statistics (Mean of addition of 1959-1966)

\begin{tabular}{|c|c|c|c|c|c|c|c|c|}
\hline & $\begin{array}{l}\text { Birth } \\
\text { rate } \\
\text { (1 for } \\
\text { top) }\end{array}$ & $\begin{array}{l}\text { Delivery } \\
\text { rate in } \\
\text { institu- } \\
\text { tion } \\
\text { (1 for } \\
\text { top) }\end{array}$ & $\begin{array}{c}\text { Crude } \\
\text { death } \\
\text { rate } \\
\text { (1 for } \\
\text { the } \\
\text { lowest) }\end{array}$ & $\begin{array}{l}\text { Infant } \\
\text { mortality } \\
\text { rate } \\
\text { (1 for } \\
\text { the } \\
\text { lowest) }\end{array}$ & $\begin{array}{l}\text { Propor- } \\
\text { tional } \\
\text { mortality } \\
\text { indicator } \\
\text { (1 for } \\
\text { top) }\end{array}$ & $\begin{array}{l}\text { Mortali- } \\
\text { ty rate of } \\
\text { A-group } \\
\text { causes } \\
\text { (1 for the } \\
\text { lowest) }\end{array}$ & $\begin{array}{l}\text { Mortali- } \\
\text { ty rate of } \\
\text { B-group } \\
\text { causes } \\
\text { (1 for the } \\
\text { lowest) } 1\end{array}$ & $\begin{array}{l}\text { Still- } \\
\text { birth } \\
\text { rate } \\
\text { (1 for } \\
\text { the } \\
\text { lowest) }\end{array}$ \\
\hline$P^{*}$ & 0.0161 & 0.0085 & 0.0071 & 0.0004 & 0.0055 & 0.0009 & 0.0043 & 0.0013 \\
\hline Honcho & 4 & 1 & 1 & 2 & 4.5 & 4 & 1.5 & 5 \\
\hline Minami & 2.5 & 3 & 2.5 & 3 & 6 & 3 & 1.5 & 4 \\
\hline Higashi & 6 & 5 & 6 & 5 & 4.5 & 6.5 & 4 & 6 \\
\hline Kita & 5 & 7 & 5 & 6 & 3 & 6.5 & 5.5 & 7 \\
\hline Ohne & 2.5 & 2 & 4 & 4 & 1 & 1.5 & 5.5 & 1 \\
\hline Nishi & 1 & 4 & 2.5 & 1 & 7 & 1.5 & 3 & 2 \\
\hline Kami & 7 & 6 & 7 & 7 & 2 & 5 & 7 & 3 \\
\hline
\end{tabular}

$\mathrm{P}^{*}$ : Incidence against population in the entire Hadano City (Mean of addition of 1959-1966.) 
is evident from the table that the yearly relative ranking is not fixed when it is examined at the level of districts with a small size of population, such as in this case. The comparatively constant yearly ranking was seen only in the rate of deliveries in institution.

Table 6 gives the ranking of each health indicator obtained by adding the pertinent figures of the vital statistics for 8 years (1959-66) for each of the seven districts.

A comparison between the ranking of the levels of health in view of the integrated physical values of schoolchildren indicated in Table 4 and the ranking of the levels of health based on the health indicators derived from the vital statistics reveals significant correlation between the integrated value of height (the ranking of the mean of both sexes) and the rate of deliveries in institution and the crude death rate. Significant correlation was also observed between the integrated value of body weight and the rate of deliveries in institution. In addition, considerably high correlation was observed between the integrated values of height or body weight and the infant mortality rate, the mortality rate of the A-group causes and that of the B-group causes.

3) In regard to the information on various environmental conditions of each of the seven districts of Hadano City, a questionnaire survey was conducted on 1081 households of 6th graders in the same city, and the information in the socio-economical considerations, which was thought to be necessary, was obtained. The response rate of the questionnaire was $95.0 \%$

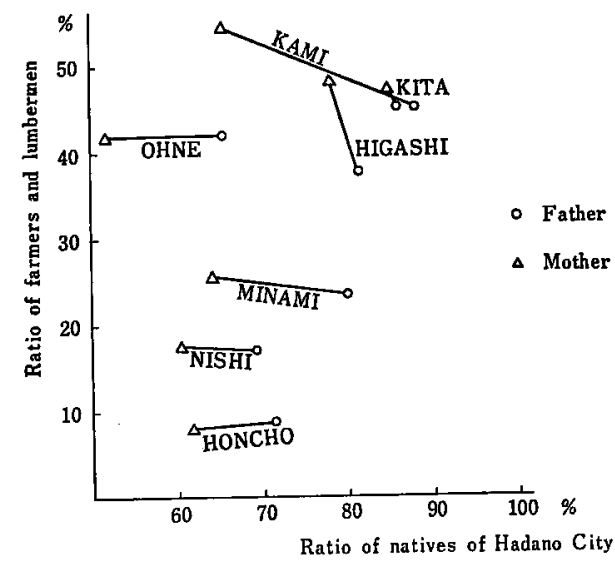

Fig. 4 The occupation and the native place of parents of 6 th graders according to school. 
for the whole city. The response rate according to school ranged from $93.6 \%$ to $100 \%$. Since the author intends to report separately ${ }^{5}$ on the detailed results of the survey for the environmental conditions according to school district, only necessary data will be described in this report. Fig. 4 shows the ratio of the natives of the same city and that of farmers and lumbermen obtained from the survey data of the native place and the occupational structure of parents for each district performed for the purpose of geting the exact informations on the environmental conditions in each school district.

A comparison of the environmental conditions in school district shown in Fig. 4 with the integrated physical values given in Tables 3, 4 and Fig. 3 reveals that the integrated values (especially height) are relatively the best in the Honcho District located in the center of Hadano City with considerable development and are relatively inferior in Kita, Kami and Higashi Districts located in the hilly part forming a closed rural area with strong indigenousness.

\section{DISCUSSION}

1) Annual Fluctuation of the Integrated Physical Value

To measure the levels of health of a given area based on the integrated physical values computed according to sex and to each of the four measurement items for each elementary school using the pre-existing physical statistical data of schoolchildren, it should be noted that the fact, as previously stated, ${ }^{1}$ there may be considerable measurement error and deviation depending on the measurement item (girth of chest and sitting height, in particular) and making an assessment based only on the values for a particular year involves considerable risk. In the case of Hadano City in fact, a comparison of the size of the annual fluctuation of the four measurement items made for each sex revealed a larger size of the annual fluctuation in girth of chest and sitting height than in height, as has been expected. The size of the fluctuation of girth of chest for females was especially large. Because of the large extent of the measurement error and deviation, the use of the pre-existing physical statistical data obtained by school staff requires a deliberate precaution. 
2) The Relativity of the Integrated Physical Values to Various Health Indicators Based on the Vital Statistics

If the integrated physical values are used for measurement of the levels of health of a small community, it is important to investigate tentatively what connection those values have with the health indicators based on hitherto used vital statistics. In Hadano City the seven school-districts, which were selected as the object for comparison, correspond with the seven old towns and villages prior to consolidation into the present city. Furthermore, in the annual reports of the Health Center in charge of the city since 1959, important figures of the vital statistics are recorded according to these old towns and villages. This is the reason why the two types of measurements have been taken up as the comparative study of the health indicators in this survey.

However, because of considerable annual variation on the side of the integrated physical values depending on the measurement item, ranking of the districts was obtained here basing on the arithmetic mean of the integrated physical values for 5 years. On the other hand, owing a low incidence appearing in a population when a health indicator is based on the vital statistics, it should be pointed out that the extremely large fluctuation of the health indicators makes a yearly comparison difficult in small communities as it was observed in the case of the infant mortality rate in Table 5. Accordingly in this report, ranking of the districts was obtained by the added value of pertinent figures of the vital statistics for the recent 8 years according to each district, as given in Table 6. Comparison between this ranking and the ranking of the integrated physical values was made.

In the case of Hadano City, significant rank correlation was observed between the integrated values of height or body weight and the rate of institutional deliveries. It should be remembered that the rate of deliveries in institution is closely associated with the geographical distribution of gynecological facilities in a given district. But such a marked difference observed in a relatively small community as in this case can be interpreted as reflecting straightforwardly the difference in the views of inhabitants about delivery, or the difference in the sense and manners of life in a broad sense, as well as the distribution of medical facilities.

In addition, the integrated physical values (particularly, height) are correlated significantly with the crude death rate. However, due to lack of the data of age composition according to district it was not possible to investigate to what extent it reflects the effect of age composition. No 
significant correlation was found between the rankings of P.M.I. or stillbirth rate and the ranking of the integrated physical values.

3) The Relation of the Integrated Physical Values to the Environmental Conditions of a Given Community

Similar to other areas in the same prefecture which the author surveyed previously (Yamato City $^{1}$ and Kamakura City ${ }^{0}$ ), in the case of Hadano City also, it has been recognized that the better physical constitution of schoolchildren (height, in particular) in a city is observed in developing area corresponding to the degree of urbanization. In view of human ecology the author, therefore, stated that the physique of schoolchildren has become a biometer for the stage of progress of "urbanization."

\section{SUMMARY}

With the purpose of discovering the indicators usable for measurement of the levels of health of a small community from among the pre-existing statistical data, the physical statistical data of schoolchildren were selected from the statistics for school health and their usability as health indicators of a given community was examined.

1) The field surveyed was Hadano City, Kanagawa Pref., (a population of $50,000-60,000)$. Using the integrated physical values stated in the previous report, measurement of the levels of health was conducted according to seven school districts in the same city. The results were examined in comparison with the results of the measurement of health levels by the eight health indicators based on the vital statistics. Among the eight health indicators which are generally used, the rate of deliveries in institution corresponded with the integrated physical values (especially height and body weight).

2) In view of the relation of the results of the integrated physical values with the environmental conditions observed according to small districts, it was observed that the relative difference seen in the integrated physical values (particularly, height) was closely associated with the progressing stage of urbanization of the pertinent district.

\section{ACKNOWLEDGEMENT}

In closing this report, the author wishes to express his sincere appreciation to Dr. Minoru Maeda and Dr. Isao Suzuki both the former Heads of Hadano 
Heailth Center, Kanagawa Prefecture and many other persons concerned for their granting great cooperation and conveniences to the survey reported in this papr.

\section{REFERENCES}

1. Kahyo, H. (1969) Physical statistics of schoolchildren as a health indicator for small communities (I). Keio J. Med. 17: 251-261.

2. Hadano Health Center: Annual report of Hadano Health Center, 1959-1966. (in Japanese)

3. Kahyo, H. (1969) Utilization of the physical statistics of schoolchildren in measurement of levels of health in community, KOSEI NO SHIHYO (Health and Welfare Statistics) 17 (2), 29-33. (in Japanese)

4. Swaroop, S. and Uemura, K. (1957) Proportional mortality of 50 years and above. Bull. Wld. Hlth. Org. 17: 439-481.

5. Kahyo, H., Suzuki, I., and Maeda, M. Physical statistics of schoolchildren as a community health indicator (Report 2). (1969) Jap. J. Publ. Hlth. 16: 561-570. (in Japanese)

6. Kahyo, H. Physical statistics of schoolchildren as a health indicator for small communities (III). (in preparation for publication) 